\title{
Retrospective study factors related to preterm birth in Government Raja Mirasudar hospital and obstetric and perinatal outcome
}

\section{Pradeepa Soundarajan*, Poovathi Muthuramu, Munira Veerapandi, Rubini Mariappan}

Department of Obstetrics and Gynaecology, Thanjavur Medical College Hospital, Thanjavur, Tamil Nadu, India

Received: 01 July 2016

Accepted: 11 August 2016

*Correspondence:

Dr. Pradeepa Soundarajan,

E-mail: prathibanagaraj@gmail.com

Copyright: (C) the author(s), publisher and licensee Medip Academy. This is an open-access article distributed under the terms of the Creative Commons Attribution Non-Commercial License, which permits unrestricted non-commercial use, distribution, and reproduction in any medium, provided the original work is properly cited.

\begin{abstract}
Background: Preterm birth is a leading cause of perinatal mortality and long-term morbidity as well as the long-term health consequences and cognitive outcomes. Present study was conducted to determine prevalence and risk factors and obstetric \& perinatal outcome associated with preterm birth in Rajamirasudar Hospital, Thanjavur.

Methods: A case control study was conducted between Mar 2015 - Sep 2015 in Rajamirasudar Hospital, Thanjavur. All the live new-borns during the study period were investigated. Of 6805 live births during the study period 356 births occurred in $<37$ weeks were taken as a case and 579 term neonates were taken as a control group. Data were obtained through review of prenatal and hospital delivery records. Univariate and multivariate logistic regression analysis were applied to obtain magnitude of association between independent variables and preterm birth.

Results: The prevalence rate of preterm birth was 5.6\%. History of previous preterm birth $(\mathrm{OR}=12.7, \mathrm{CI}$ : $3.9-40.4$, $\mathrm{p}<0.001)$, hypertension ( $\mathrm{OR}=7.3$, CI: 2.1-25.4, $\mathrm{p}=0.002)$, oligohydramnios $(\mathrm{OR}=3.9, \mathrm{CI}: 1.6-9.5$, $\mathrm{p}=0.002)$, diabetics $(\mathrm{OR}=3.7, \mathrm{CI}: 1.1-11.8, \mathrm{p}=0.024)$, premature rupture of membrane $(\mathrm{OR}=3.1, \mathrm{CI}: 1.9-4.9, \mathrm{p}=0.000)$, hypothyroid $(\mathrm{OR}=2.0, \mathrm{CI}: 1.0-3.8, \mathrm{p}=0.037)$, prepregnancy low $\mathrm{BMI}(\mathrm{OR}=2.0, \mathrm{CI}: 1.1-3.8, \mathrm{p}=0.015)$, urinary tract infection in 2630 weeks , $(\mathrm{OR}=1.8 \mathrm{CI}: 1.0-3.2, \mathrm{p}=0.04)$ were determined as significant risk factors for preterm birth.

Conclusions: Early detection and treatment of diseases or disorders among pregnant women especially hypertension, Oligohydramnios, diabetics, hypothyroid, urinary tract infection, pre pregnancy low BMI as well as the improving health care quality delivered to pregnant women may reduce preterm prevalence rate and also reduce neonatal morbidity and mortality.
\end{abstract}

Keywords: Prevalence, Preterm birth, Risk factors, Perinatal outcome

\section{INTRODUCTION}

Preterm birth, childbirth occurring at less than 37 completed weeks of gestation, is the direct cause for $24 \%$ of neonatal deaths. ${ }^{1}$ Rates of preterm birth have been reported to range from $5-7 \%$ of live births in some developed countries and are estimated to be substantially higher in developing countries. Comparing with children born at term, preterm infants face to higher risk of several disabilities including neuro-developmental impairments, gastrointestinal complications, cerebral palsy, sensory deficits, learning disabilities, and respiratory illness. ${ }^{3}$ The morbidity associated with preterm birth often extends to later life resulting in physical, psychological, and economic costs. ${ }^{4}$ The precise role of events linked to an increased risk of preterm birth is unknown. ${ }^{5}$

Maternal job status, educational level, gravidity, history of periodontal infection, and history of urinary infection have no significant relationships with preterm birth. ${ }^{6}$ Mahmoodi et al found no significant relationships between preterm birth and maternal factors (i.e. age, education, and pre-pregnancy body mass index). Significant relation was observed between maternal age and premature rupture of membranes (PROM) and PROM was also related to preterm birth significantly. ${ }^{7}$ 
Similar study in Yasuj found the risk of preterm labor in women with history of diabetes mellitus, thyroid dysfunction to be 2.3 times higher than healthy mothers. ${ }^{8}$

Estimation of preterm birth rates is required to implement interventions in order to reduce the risk of premature labor and delivery. ${ }^{9}$ Prevalence of preterm delivery in different cities of Iran is in a range of 5.6-39.4\%. ${ }^{10}$ The etiology of preterm birth is multi factorial and it is affected by social, psychological, biological and genetic factors. Its prevalence also depends on the geographical and demographic features. This study was carried out to determine the prevalence and risk factors and obstetrics and perinatal outcome associated with preterm birth in Rajamirasudar Hospital, Thanjavur.

\section{METHODS}

All pregnant women hospitalized for delivery in $\mathrm{RMH}$, Thanjavur were included in a case control study conducted from March 2015 to September 2015. Gestational age was estimated using either the first day of the last normal menstrual period or first trimester obstetric ultrasound. Preterm birth, defined as birth occurred in gestational age of less than 37 complete weeks. Termination of pregnancy before 22 weeks of gestation (miscarriage), stillbirth after 22 weeks of gestation, multiple birth, abnormality in uterine, cervical cerclage were excluded from the study. Including criteria for cases were defined as singleton live births occurred in less than 37 complete weeks. Control group considered as the singleton live births occurred at 37 or more completed weeks of gestation.

Of 6805 live births during the study period 356 births occurred at < 37 completed weeks and they were considered as cases. Control group $(\mathrm{N}=579)$ was randomly selected from singleton live births occurred at 37 or more completed weeks of gestatation. Data were collected retrospectively through review of prenatal and hospital delivery records using a self-designed questionnaire.

The questionnaire contained socio-demographic factors and maternal and prenatal care characteristics of current and previous pregnancies. Socio-demographic factors included: age, education level, social class, maternal occupation, parents' consanguinity, and area of residence (rural or urban). Maternal and prenatal care characteristics in current pregnancy covered body mass index, maternal height, gestational diabetes, hypothyroid, hypertension in pregnancy, low systolic blood pressure $(\leq 100)$, urinary tract infection, preterm rupture of membrane, location of placenta, amniotic fluid volume, infertility history and treatment, mode of delivery, congenital abnormalities.

Previous pregnancy and reproductive history characteristics included; gravidity, parity, history of abortion, number of previous abortion, history of still birth, history of preterm labor. The term gestational hypertension was used for woman with hypertension (i.e. blood pressure $\geq 140 / 90 \mathrm{mmHg}$ ) after 20 weeks of gestation. ${ }^{11}$ Chronic hypertension also included in or study.

Urinary tract infection is diagnosed where asymptomatic bacteruria was present on positive urine culture test, premature rupture of membrane or leakage of amniotic fluid referred to a rupture that occurred before the onset of regular contraction or before 37 weeks of pregnancy. ${ }^{12,13}$ For oligohydraminos AFI $<5 \mathrm{~cm}$ is taken as a cut off value. Perinatal outcome of the baby also evaluated. This project was approved by ethical committee of Thanjavur medical college, Thanjavur.

\section{Statistical analysis}

Chi-square was employed to compare distribution of variables between the groups; univariate analysis was applied to evaluate associations between independent variables and preterm birth. In order to highlight important risk factors for preterm birth, multivariate regression analysis was conducted and all the variables displaying significant relationships with preterm birth in the univariate analysis were entered into the model (Forward Wald Model). For the logistic regression, results are reported as odds ratios and $95 \%$ confidence intervals (CI) along with $\mathrm{P}$ value.

\section{RESULTS}

Out of 6805 live newborns delivered, 356 (5.6\%) were preterm. Among the variables considered as socioeconomic characteristics, only social class of parents was significantly correlated with preterm delivery $(\mathrm{OR}=1.4, \mathrm{CI}: 1.0-1.8, \mathrm{p}=0.016)$. The results for statistical analysis of maternal and prenatal care characteristics of the subjects in current pregnancy in relation with preterm birth are summarized in Table 1.

Table 1: Body mass index.

\begin{tabular}{|llllll|}
\hline Body mass index & Preterm n $(\%)$ & Term n $(\%)$ & Total $n(\%)$ & OR (95\% CI) & p-value \\
\hline$<19 / 8$ & $39(12.5)$ & $51(9.3)$ & $90(10.4)$ & $1.27(0.80-2.01)$ & 0.305 \\
\hline $19 / 8-26$ & $158(50.5)$ & $263(47.8)$ & $421(48.8)$ & $1($ ref $)$ & ref \\
\hline $26 / 1-29 / 9$ & $67(21.4)$ & $143(26.0)$ & $210(24.3)$ & $0.78(0.54-1.10)$ & 0.465 \\
\hline $30 \leq$ & $49(15.7)$ & $93(16.9)$ & $142(16.5)$ & $0.87(058-1.30)$ & 0.518 \\
\hline
\end{tabular}


Table 2: Maternal height.

\begin{tabular}{|llllll|}
\hline Maternal height & Preterm n $(\%)$ & Term n (\%) & Total n (\%) & OR (95\% CI) & p-value \\
\hline $155>$ & $101(30.9)$ & $140(24.7)$ & $241(27.0)$ & $1.36(1.00-1.84)$ & 0.046 \\
\hline $155 \leq$ & $226(69.1)$ & $426(75.3)$ & $652(63.0)$ & $1($ ref $)$ & \\
\hline
\end{tabular}

Table 3: Obstetric variables.

\begin{tabular}{|c|c|c|c|c|c|}
\hline Gestational diabetes & Preterm n (\%) & Term n (\%) & Total n $(\%)$ & OR $(95 \% \mathrm{CI})$ & p-value \\
\hline Yes & $15(4.4)$ & $11(1.9)$ & $26(2.8)$ & $2.41(1.09-5.32)$ & 0.029 \\
\hline No & $323(95.6)$ & $572(98.1)$ & $895(97.2)$ & 1 (ref) & \\
\hline Hypertension & $17(5.0)$ & $8(1.4)$ & $25(2.7)$ & $4.0(1.71-9.40)$ & 0.001 \\
\hline Preeclampsia & $28(8.2)$ & $12(2.0)$ & $40(4.3)$ & $4.40(2.20-8.81)$ & 0.000 \\
\hline No hypertension & $298(86.9)$ & $566(96.6)$ & $864(93.0)$ & 1 (ref) & Ref \\
\hline \multicolumn{6}{|l|}{ Hypothyroid } \\
\hline Yes & $57(16.6)$ & $62(10.5)$ & $119(12.9)$ & $1.69(1.14-2.49)$ & 0.008 \\
\hline No & $286(83.4)$ & $526(89.5)$ & $812(87.2)$ & 1 (ref) & \\
\hline \multicolumn{6}{|l|}{$\begin{array}{l}\text { Urinary tract infection } \\
\text { during pregnancy }\end{array}$} \\
\hline Yes & $61(18.4)$ & $71(12.5)$ & $132(14.7)$ & $1.57(1.08-2.29)$ & 0.016 \\
\hline No & $271(81.6)$ & $498(87.5)$ & $769(85.3)$ & 1 (ref) & \\
\hline \multicolumn{6}{|l|}{$\begin{array}{l}\text { Preterm rupture of } \\
\text { membrane }\end{array}$} \\
\hline Yes & $95(28.7)$ & $96(16.6)$ & $191(21.0)$ & $2.02(1.46-2.79)$ & 0.000 \\
\hline No & $236(71.3)$ & $483(83.4)$ & $719(79.0)$ & 1 (ref) & \\
\hline \multicolumn{6}{|l|}{ Dental problems } \\
\hline Yes & $136(43.3)$ & $267(49.4)$ & $403(47.1)$ & $0.78(0.593-1.03)$ & 0.088 \\
\hline No & $178(56.7)$ & $274(50.6)$ & $452(52.9)$ & 1 (ref) & \\
\hline \multicolumn{6}{|l|}{ Location of placenta } \\
\hline Anterior & $132(46.5)$ & $227(43.7)$ & $359(44.7)$ & $1.04(0.710-1.55)$ & 0.811 \\
\hline Posterior & $88(31.0)$ & $164(31.5)$ & $252(31.3)$ & $0.96(0.63-1.46)$ & 0.878 \\
\hline
\end{tabular}

Table 4: Mode of delivery.

\begin{tabular}{|llllll|}
\hline Mode of delivery & Preterm $n(\%)$ & Term $n(\%)$ & Total $n(\%)$ & OR $(95 \%$ CI $)$ & p-value \\
\hline Normal delivery & $135(39.0)$ & $194(32.9)$ & $329(35.2)$ & $1.30(0.98-1.71)$ & 0.060 \\
\hline Caesarian delivery & $211(61.0)$ & $395(67.1)$ & $606(64.8)$ & $1($ ref $)$ & \\
\hline
\end{tabular}

Table 5: Fetal outcome.

\begin{tabular}{|c|c|c|c|c|c|}
\hline Perinatal outcome: RDS & Preterm n (\%) & Term n (\%) & Total n (\%) & OR $(95 \% \mathrm{CI})$ & p-value \\
\hline Yes & $137(41.5)$ & $197(34.7)$ & $334(37.2)$ & $1.33(1.00-1.76)$ & 0.043 \\
\hline No & $193(58.5)$ & $380(65.3)$ & $563(62.8)$ & 1 (ref) & \\
\hline Birth asphysia & Preterm n $(\%)$ & Term n (\%) & Total n (\%) & OR $(95 \% \mathrm{CI})$ & p-value \\
\hline Yes & $55(16.3)$ & $49(6.7)$ & $94(10.2)$ & $2.71(1.75-4.19)$ & 0.000 \\
\hline No & $283(83.7)$ & $545(93.3)$ & $828(89.8)$ & 1 (ref) & \\
\hline
\end{tabular}

The odds of delivering a preterm birth was significantly high among the women with short stature, gestational diabetes, pre-eclampsia, hypertension, hypothyroid, urinary tract infection during pregnancy, preterm rupture of membrane, Oligohydramnios. Comparing to control group, although the differences were not statistically significant, we observed higher prevalence rates of preterm birth in women with; BMI $19 / 8<\mathrm{Kg} / \mathrm{m} 2$, polyhydramnios, pregnancy through In vitro fertilization (IVF), pregnancy through ovular stimulator drugs consumption and congenital abnormalities.

Women with previous experience of abortion, a birth interval of less than 3 years, history of preterm birth, and 
women with history of low birth weight delivery significantly were more likely to deliver preterm infant. We observed incidence rates of preterm birth to be higher in women with three or more parity, experiencing three or more previous abortions, history of still birth, and history of delivering term low birth weight, however, the differences were not statistically significance. Based on the results obtained from multivariate analysis; history of preterm birth, hypertension during pregnancy, oligohydramnios, premature rupture of membrane, hypothyroid, urinary tract infection during pregnancy, diabetics were identified as significant risk factors for preterm birth delivery.

\section{DISCUSSION}

The prevalence of preterm birth found in current study $(5.6 \%)$ is appreciably lower than the rates reported for African (12.6\%) and European countries (6.7\%) but is higher than rate of $4.4 \%$ reported for Italy. ${ }^{14}$ The low rate of preterm birth found in present study might reflect success of different programs introduced by Tamilnadu Health ministry to improve health service quality delivered to pregnant women including pre-pregnancy and pregnancy health care in the last decade.

Experience of previous preterm birth was identified as the most significant risk factor for preterm birth with odds ratio of 12.7. This study found that women with previous preterm delivery were at increased risk for their next pregnancy. ${ }^{15}$ The recurrence risk in women with a previous preterm delivery ranges from $15 \%$ to more than $50 \%$ depending on the number and gestational age of previous deliveries. The mechanism for this has not been well understood, it can occur in women with prior spontaneous labor as well as those with inducing preterm birth.

Medical disorders like (e.g. gestational diabetes, hypertension, and obesity) that tend to last from one pregnancy to the next, might explain many repetitive spontaneous and induced preterm births. Hypertension and pre-eclampsia that increased the risk of preterm birth by 7.3 and 3.6 folds, respectively.

Hypertension causes vasospasm in uterine vessels and reduce uterplacental flow which in turn causes intrauterine growth restriction. ${ }^{16}$ High rate of disorders like placenta abruption and pre-eclampsia and intrauterine growth restriction among women with hypertension may results in surgical operations and preterm birth. Renzo et al reported the likelihood of preterm birth to be 2.6 times greater among women with chronic hypertension. ${ }^{5}$

Some reports have estimated the likelihood of preterm birth to be 3-10 times higher in women with Oligohydramnios. ${ }^{17}$
In our study PROM is the most common cause of Oligohydramnios. ${ }^{11}$ Similar to present study preterm rupture of membrane has been reported to be related significantly to preterm birth. ${ }^{7}$ Some studies have not found hypothyroid to be a risk factor for preterm delivery. ${ }^{18}$ However, similar to our findings, others reported that the risk of prematurity to increase 1.3 times in women who suffered from hypothyroid.

The infection of the urinary system is the most prevalent bacterial infections occurred during pregnancy. Similar to our results, Schieve et al has considered urinary system infection as a risk factor for premature birth. ${ }^{19}$ Infection may raise release of inflammatory chemokine's and cytokines such as interleukins and tumor necrosis factors. Microbial endotoxins and proinflammatory cytokines stimulate the production of prostaglandins (other inflammatory mediators) and matrix-degrading enzymes that finally result in stimulation of uterine contractions, preterm rupture of the membrane, and preterm birth. ${ }^{20}$ RDS and Birth asphyxia significantly associated with preterm birth, which is agreement with findings where the risk of RDS and asphyxia was higher in women with preterm. $^{21,22}$

The data for some variables were collected based on the medical records of the subjects and that; there might be a potential risk for quality of recorded data. Other limitation was that, where the mothers did not remember the date of the first day of last menstrual period accurately, we calculated gestational age by obstetric ultrasound taken in first trimester. To insure the accuracy of data the obstetric ultrasound should be performed by the same person and the same machine for all participants; while it was not possible in our study.

\section{CONCLUSION}

History of preterm birth, hypertension, preterm rupture of the membrane, oligohydramnios, diabetics, urinary infection, hypothyroid were identified as the most important risk factors for preterm birth. Identifying pregnant women at the risk of preterm delivery and proving quality healthcare may decrease the rate of preterm birth and its consequences.

\section{ACKNOWLEDGEMENTS}

I gratefully acknowledge and express my sincere thanks to our Dean, Thanjavur Medical College and hospital, Thanjavur, India for allowing me to do this study and utilizing the Institutional facilities. I would also like to thank all the medical and para-medical staffs who have helped me complete this study. A special thanks to all the patients who willingly co-operated and participated in this study. I would like to thank all my colleagues and friends who have been a constant source of encouragement to me. My co-author Dr. M. Poovathi read and approved the final manuscript. 
Funding: No funding sources

Conflict of interest: None declared

Ethical approval: The study was approved by the Institutional Ethics Committee

\section{REFERENCES}

1. Beck S, Wojdyla D, Say L, Betran AP, Merialdi M, Requejo $\mathrm{JH}$, et al. The worldwide incidence of preterm birth: a systematic review of maternal mortality and morbidity. Bull World Health Organ. 2010;88:31-8.

2. Sonkusare S, Rai L, Naik P. preterm birth: mode of delivery and neonatal outcome. Med J Malaysia. 2009;64:303-06.

3. Modarres SZ, Amooian B, Movahed SB, Mohamadi M. periodontal health in mothers of preterm and term infants. Taiwan J Obstet Gynecol. 2007;46:157-61.

4. Goldenberg RL, Culhane JF, Jams JD, Rometo R. epidemiology and cause of preterm birth. Lancet. 2008;371:75-83.

5. Renzo GCD, Giardina I, Rosati A, Clerici G, Torricelli M, Petraglia F. maternal risk factors for preterm birth: a country-based population analysis. Eur J Obstet Gynecol. 2011;3:1-5.

6. Mirzaie F, Mohammad-Alizadeh S. Contributing Factors of preterm delivery in parturient in a university hospital in Iran. Saudi Med J. 2007;28:400-4.

7. Mahmoodi Z, Hoseini F, Sadeghi Avval Shahr H, Ghodsi Z, Amini L. The Association between Maternal Factors and Preterm Birth and Premature Rapture of Membranes. J Fam Reprod Health. 2010;4:135-9.

8. Nabavizadeh SH, Malekzadeh M, Mousavizadeh A, Ghaffarian Shirazi HR, Ghaffari P, Karshenas N, et al. Retrospective study of Factors related to preterm labor in Yasuj, Iran. Int J Gen Med. 2012:1013-10.

9. Raisanen S, Gissler M, Saari J, Kramer M, Heinonen S. Contribution of risk factors to Extremely, Very and Moderately Preterm Birts-Register-Based Analysis of 1,390.742 Singleton Births. PLOS One. 2013;8:1-7.

10. Dolatian M, Mirabzadeh A, Forouzan AS, Sajjadi H, Alavi Majd H, Moafi F. Preterm Delivery and Psycho-Social Determinants of Health Based on
World Health Organization Model in Iran: A Narrative Review. Glob J Health Sci. 2013;5:52-64.

11. Cunningham FG, Leveno KJ, Hauth JC, editors. Williams obstetrics. 23th Ed. New York: McGraw Hill; 2010.

12. Jafari F, Eftekhar H, Pourreza A, Mousavi J. Sosioeconomic and medical determination of low birth weight in iran: 20 years after establishment of a primary health care network. Public Health.2010;124:153-7.

13. Vallandares E, Ellsberg M, Pena R, Hogberg U, Persson LA. Physical partner abuse during pregnancy: a risk factor for low birth weight in Nicaragua. Obstet Gynecol. 2002;100:700-4.

14. Nguyen N, Savitz DA, Thorp JM. Risk factors for preterm birth in Vietnam. Int $\mathbf{J}$ Gynaecol Obstet. 2004;86:70-8.

15. Khalajinia Z, Jandaghi G. Maternal risk factors for preterm birth: a country-based population analysis. Eur J Obstet Gynecol Reprod Biol. 2012;159:342-6.

16. Bernabe JV, Soriano T, Albaladejo R, Juarranz M, Calle ME, Martinez D, et al. Risk factors for low birth weight: a review. Eur J Obstet Gynecol Reprod Biol. 2004;116:3-15.

17. Chin LO C, Hsu JJ, Hsieh CC, Hsieh TT, Hung T. Risk factors for spontaneous preterm delivery before 34 weeks of gestation among Taiwanese women. Taiwan J Obstet Gynecol. 2007;46:389-93.

18. Coker AL, Sanderson M, Dong B. Partner violence during pregnancy and pregnancy outcomes. Paediatr Perinat Epidemiol. 2004;18:260-90.

19. Schieve L, Handler A, Hershow R, Persky V, Davis F. Urinary tract infection during pregnancy: its association with maternal morbidity and perinatal outcome. Am J Public Health. 1994;84:806-15.

20. Rodrigues T, Rocha L, Barros H. Physical abuse during pregnancy and preterm delivery. AM J Obstet Gynecol. 2008;198:1-6.

21. De Sutter P, Bontinck J, Schutysers V, Van der Elst J, Gerris J, Dhont M. First trimester bleeding and pregnancy outcome in singletons after assisted reproduction. Hum Reprod. 2006;21:1907-11.

22. Strobino B, Pantel-Silverman J. Gestational vaginal bleeding and pregnancy outcome. Am J Epidemiol. 1989;129:806-15.

Cite this article as: Soundarajan $\mathrm{P}$, Muthuramu $\mathrm{P}$, Veerapandi M, Mariappan R. Retrospective study factors related to preterm birth in Government Raja Mirasudar hospital and obstetric and perinatal outcome. Int J Reprod Contracept Obstet Gynecol 2016;5:3006-10. 